Pesquisa e Reflexão em Educação Básica

\title{
Cascão lava as mãos como medida de enfrentamento à COVID-19: os artefatos culturais e suas pedagogias
}

Lucas Pacheco Brum ${ }^{1}$ Marcos Vinícius Silva Magalhães² Sandra Monteiro Lemos ${ }^{3}$

\begin{abstract}
Resumo:
Posicionado dentro da vertente pós-estruturalista, o presente ensaio se insere no campo das pedagogias culturais e dos estudos de cultura visual e buscou traçar alguns apontamentos acerca das representações e dos regimes de visualidade do personagem Cascão, constantes no artefato cultural criado por Mauricio de Sousa. Nessa perspectiva buscou-se reconhecer as representações ali presentes identificando suas relações com a própria cultura na contemporaneidade. 0 estudo indica que $o$ artefato produzido, ao atravessar o momento atual, produz narrativas que buscam legitimar discursos e políticas de prevenção frente à pandemia da COVID-19, operando na cultura, determinando e educando sujeitos, corpos, atitudes e valores. Desse modo, o texto foi estruturado em duas partes, em que no primeiro momento debruçou-se a apresentar o lugar de produção dessas imagens dentro da cultura. No segundo momento do texto buscou-se destacar as visualidades produzidas por Maurício de Sousa imbricadas aos regimes de visualidade, reconhecendo, assim, as pedagogias culturais como construção de subjetividades.
\end{abstract}

\section{Palavras-chave:}

Pedagogia cultural. Representação. Cascão. Pandemia. Regimes de visualidade.

\footnotetext{
1 Doutorando em Educação; Universidade Federal de Pelotas (UFPeL). E-mail lukaspachecobrum@yahoo.com ORCID iD: https:// orcid.org/0000-0001-7655-8463

2 Doutorando em Artes Visuais; Universidade de Brasília (UnB). E-mail: marvimagalhaes@gmail.com ORCID iD: https://orcid. org/0000-0001-7752-5671

3 Doutora em Educação; Universidade Estadual do Rio Grande do Sul (UERGS). E-mail: montlemos@gmail.com ORCID iD: https://orcid.org/0000-0003-3517-1953
} 


\section{Cascão washes his hands as a way of facing COVID-19: the cultural artifacts and their pedagogies}

\section{Abstract:}

The present text installs itself in the field of cultural pedagogies and of the cultural visual studies and sought to draw some appointments about the representations and the regimes of visuality of the character Cascão, persistent into the cultural artifact created by Mauricio de Sousa. In this perspective it sought to recognize the representations there presents identifying their relations with culture itself in contemporaneity. The study denotes that the artifact produced, when getting through the current moment, it produces narratives that pursue to legitimize discourses and policies of prevention facing the COVID-19 pandemic, operating in culture, defining and educating subjects, bodies, behaviors and values. In this way, the text was structured in two parts, in which at the first moment it bent on presenting the place of production of these images within the culture. In the second part of the text, we sought to highlight how visualities produced by Maurício de Sousa imbricated to regimes of visuality, thus recognizing cultural pedagogies as the construction of subjectivities.

\section{Keywords:}

Cultural Pedagogy. Representation. Cascão. Pandemic. Regimes of visuality.

\section{Cascão se lava las manos para afrontar el COVID-19: artefactos culturales y sus pedagogías}

\section{Resumen:}

Este texto se inserta en el campo de las pedagogías culturales y los estudios de la cultura visual y buscó trazar algunas notas sobre las representaciones y regímenes visuales del personaje Cascão, contenidos en el artefacto cultural creado por Mauricio de Sousa. En esta perspectiva, buscamos reconocer las representaciones allí presentes identificando sus relaciones con la propia cultura en la época contemporánea. El estudio indica que el artefacto producido, al atravesar el momento actual, produce narrativas que buscan legitimar discursos y políticas de prevención frente a la pandemia COVID-19, operando en la cultura, determinando y educando sujetos, cuerpos, actitudes y valores. De esta forma, el texto se estructuró en dos partes, en las que en un primer momento se dedicó a presentar el lugar de producción de estas imágenes dentro de la cultura. En la segunda parte del texto, buscamos resaltar las visualidades producidas por Maurício de Sousa imbricadas a los regímenes de visualidad, reconociendo así las pedagogías culturales como la construcción de subjetividades.

\section{Palabras clave:}

Pedagogía cultural. Representación. Cascão. Pandemia. Regímenes de visualidad. 


\section{Introdução}

\section{Imagem 1 - Selo digital: "Cascão, nosso embaixador das mãos limpas!". Mauricio de Sousa Produções, 2020.}

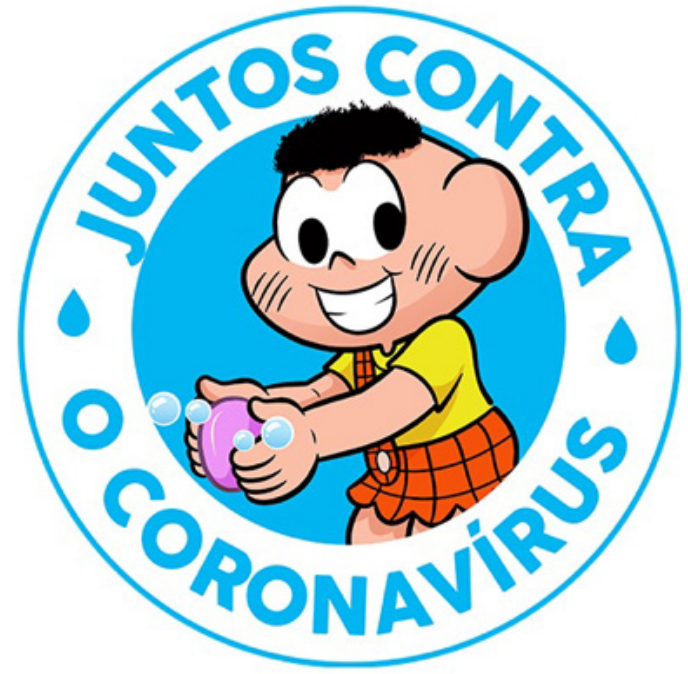

Fonte: Site da Turma da Mônica no UOL .

Os(as) personagens criados(as) pelo cartunista brasileiro Mauricio de Sousa (1935) ainda povoam o imaginário de pessoas de todas as idades, sobretudo o de crianças e adolescentes. Desde a criação dos(as) primeiros(as) personagens, no final da década de 1950, até às primeiras publicações nas revistas no formato das histórias em quadrinhos (HQ) - gibis -, ainda na década de 1970, é comum identificarmos que muitos(as) brasileiros(as) já se viram lendo essas histórias. Muitas são as subjetivações possíveis a partir das narrativas de seus(suas) personagens. A didatização de tais artefatos, mais especialmente no contexto escolar, se destaca por perpetuar as imagens e as narrativas presentes nas histórias da Turma da Mônica (CUNHA, 2014; GUAREZI, 2016; SANTANA, 2007).

Assim, o presente texto se inicia com a emblemática imagem do personagem Cascão ${ }^{5}, \mathrm{o}$ qual é representado em uma ação que contraria suas características identitárias e subjetividades originais. Cascão, um dos personagens que integra as histórias e aventuras da Turma da Mônica, foi criado pelo autor em 1961, e é conhecido popularmente como um menino que não gosta de tomar banho, estando sempre sujo, tendo aversão à água e à limpeza. O personagem adora jogar futebol, é amigo inseparável de Cebolinha, e aceita as investidas e os planos do amigo contra a personagem Mônica e seu coelho de pelúcia Sansão ${ }^{6}$. Porém, os planos sempre acabam falhando e o final das histórias são, de algum modo, sempre previsíveis.

Desde os tempos de sua criação, embora se reconheça que a essência dessas histórias e as características de seus(suas) personagens permaneçam as mesmas, de algum modo, é possível identificar algumas mudanças que impactam suas visualidades, especialmente ao considerarmos um tempo e um espaço específico. Eis o mote principal desse estudo ao problematizar o modo como o personagem Cascão foi impactado pela pandemia causada pela COVID-19. Pois, ao que

4 Disponível em: http://turmadamonica.uol.com.br/juntoscontraocoronavirus/. Acesso em: 20 out. 2020.

50 personagem Cascão, criado pelo cartunista brasileiro Mauricio de Sousa foi baseado em um amigo do seu irmão Márcio que, em um sentido irônico, também não gostava de tomar banho e não dava a devida importância aos métodos de higiene. Contudo, a amizade entre os dois se desfez e Mauricio se esqueceu de seu nome verdadeiro. Mas em uma revista, publicada em 1972, foi revelado que o nome legítimo da pessoa que inspirou o personagem é de Cássio Marques de Araújo e que Cascão foi apenas seu apelido por causa do hábito de andar sempre sujo.

6 Cebolinha, Mônica e Sansão são outros personagens integrantes da Turma da Mônica. 
nos parece, em consonância com a nova dinâmica social vivenciada atualmente, os(as) leitores(as) e fãs da Turma da Mônica se surpreenderam ao se depararem com as novas ações e características atribuídas ao personagem Cascão.

Dadas as circunstâncias impostas pela pandemia da COVID-19 desde o início do ano de 2020, em que a sociedade buscou novas configurações e meios de sobrevivência, o mundo inteiro se viu em estado de alerta frente à obrigatoriedade das novas condições de cuidado sanitário. Assim, em meio às incertezas, buscou-se a ressignificação de novos valores, de modo a instituir novos modos de interação, legitimação e trabalho. Nesse sentido, questiona-se: qual foi a reação do personagem Cascão? Consideramos que a mudança na visualidade do personagem parece ter rompido com seus próprios hábitos, discursos e sua personalidade, assumindo um papel importante no acesso à informação e na educação de crianças, adolescentes e leitores(as), somando esforços à campanha "juntos contra o coronavírus".

Tomamos como análise o selo digital criado pela produção de Mauricio de Sousa, tal como apresentado no início do texto, o qual foi disponibilizado gratuitamente para download pelo site - http://turmadamonica.uol.com.br/juntoscontraocoronavirus/ -, e que buscou reforçar a nova postura do personagem frente aos processos pedagógicos que se instituíram na contemporaneidade. A nova visualidade do personagem, intitulada de "Cascão, nosso embaixador das mãos limpas!", contribuiu para as ações de prevenção e conscientização de uma nova ordem sanitária. Sob tais aspectos, isso significa considerar as visualidades como "portadoras e mediadores de significados e posições discursivas que contribuem para pensar o mundo e nós mesmos como sujeitos. Em suma, fixam a realidade de como olhar e nos efeitos que têm em cada um ao ser visto por essas imagens" (HERNÁNDEZ, 2011, p. 33).

Nesse sentido, o presente ensaio analisa o artefato cultural, protagonizado pelo personagem Cascão, reconhecendo-o como uma pedagogia cultural. Ao considerar os impactos sofridos em sua visualidade, buscaremos aportes nos estudos sobre a cultura visual. Desse modo, buscamos discutir e criar alguns relevos sobre a potência pedagógica da imagem presente no artefato analisado, que tem operado na cultura contemporânea e nos modos como a mesma tem produzido discursos legitimados sobre educação. Tais discursos incidem sobre a formação de sujeitos, hábitos, corpos, valores, em que diversas são as subjetividades que vêm sendo construídas. Especialmente em tempos pandêmicos, $\mathrm{o}$ artefato protagonizado pelo personagem Cascão pode estar instituindo novos regimes de verdade, sobretudo frente à nova realidade imposta, ou seja, pedagogicamente, vem produzindo novos modos de conduta.

Partindo desses apontamentos, o presente estudo se insere no campo das pedagogias culturais e dos estudos da cultura visual, entendendo tais campos como produtores de conhecimento. Desse modo, ao bricolar esses dois campos que têm como vertente o pós-estruturalismo dos estudos culturais ${ }^{8}$, o fazemos com o entendimento de que todos os embates de poder se dão na cultura, portanto reconhecemos a potência do pedagógico e a maneira contundente como os artefatos culturais carregam visualidades, em que "o poder é organizado e difundido" (STEINBERG; KINCHELOE, 2004, p. 14).

\footnotetext{
7 É importante destacar que a campanha "juntos contra o coronavírus" foi lançada pelo Conselho Federal de Enfermagem (Cofen), juntamente com o Governo Federal, no início da pandemia, em 2020, para assegurar a disponibilidade de Equipamentos de Proteção Individual (EPIs), para contribuir para as políticas de prevenção e saúde e também para atualizar os protocolos de atendimento aos pacientes com COVID-19. Nesse cenário, a campanha teve como objetivo difundir informações e atualizar o conhecimento acerca da pandemia. Com a propagação do vírus, logo a campanha se espalhou pelas redes sociais, entre diferentes empresas, cooperativas, órgãos privados e públicos, de modo que até as pessoas com maior popularidade nas redes sociais aderiram à campanha. Maiores informações sobre essa ação estão disponíveis pelo site: www.juntoscontracoronavirus.com.br. Acesso em: 22 nov. 2020. 8 Os estudos culturais são um campo de teorização e investigação que têm origem, de forma organizada, na fundação do Centre for Contemporary Cultural Studies (CCCS), Universidade de Birmingham, Inglaterra, em 1964. Os Estudos Culturais tiveram como ponto de partida as preocupações como: as formas culturais, as práticas culturais e as relações entre sociedade e cultura contemporânea. Uma discussão mais aprofundada sobre esse campo teórico ver em (HALL, 2019; COSTA, 2010; COSTA; VEIGA-NETO, 2004; MATTELART; NEVEU, 2004; KELLNER, 2001).
} 
Sendo assim, compreendemos as publicações e o contexto de criação dos(as) personagens da Turma da Mônica, mais especificamente a visualidade do Cascão, como artefatos produzidos dentro da cultura, dentro da configuração de um tempo e espaço específico - o da pandemia -, reforçando subjetividades na construção do modo de ser dos sujeitos. Nesse sentido, essas visualidades operam como territórios de educação e formação, uma vez que essa pedagogia "ocorre numa variedade de locais sociais" (STEINBERG, 1997, p. 101). Assim, a mesma autora pontua ainda que, esses "locais pedagógicos são aqueles onde o poder se organiza e se exercita, tais como as bibliotecas, TV, filmes, jornais, revistas, brinquedos, anúncios, videogames, livros, esportes, etc." (STEINBERG, 1997, p. 101-102).

Nessa perspectiva, o personagem Cascão é compreendido como uma figura emblemática e como uma pedagogia, como também os seus discursos que circulam no momento posto. Uma vez que as visualidades se configuram como um "lugar onde se criam e discutem significados" (MIRZOEFF, 2003, p. 19), experiências, valores, identidades e subjetividades a partir das relações de poder, de tal modo que as pedagogias culturais existem "em qualquer lugar em que o conhecimento é produzido, em qualquer lugar em que existe a possibilidade de traduzir a experiência e construir verdades" (GIROUX; MCLAREN, 1995, p. 144).

Sob tais aspectos, ao discorrer num primeiro momento do texto sobre as questões iniciais de um artefato cultural específico e o modo como essas questões reverberam na contemporaneidade, o cerne da discussão, em seguida, estará firmado sobre a visualidade do personagem Cascão. Nessa perspectiva, serão apresentadas algumas vicissitudes repentinas, ocasionadas a partir da crise de saúde pública em âmbito global e no regime de visualidade inserido dentro de um determinado contexto social e cultural. Assim, acentuamos alguns relevos nos modos como as imagens também são decorrentes das circunstâncias emergentes.

\section{Regimes de visualidade: uma mudança de ênfase das pedagogias}

Segundo o professor e autor Boaventura de Sousa Santos (2020), ao considerar uma "cruel pedagogia do vírus", várias são as problemáticas impostas pelo processo de isolamento social o qual, com notoriedade, compreendemos na prática o que implica essa realidade e o modo como as raízes nas quais se firmam a sociedade poderão estar abaladas. A metáfora "pedagogia do vírus", usada pelo autor, amplia o nosso horizonte e nos ajuda a pensar nas imagens relacionadas ao contexto pandêmico, as quais são produzidas para este momento posto, estando implicadas na produção e gerenciamento da vida das pessoas.

Dessa forma o vírus, em um sentido metafórico, se tornou um pedagogo diante das atuais circunstâncias em que vivemos. E esse tipo de relação se tornou evidente a partir de um conjunto de visualidades operacionais, tais como cartazes, cartilhas, imagens televisivas, jornalísticas, outdoors e propagandas, que discursam "desde os métodos corretos de lavar as mãos, higienizar os alimentos e utilizar as máscaras até os comportamentos adotados quando têm que sair às ruas, ir aos supermercados, farmácias, hospitais e cemitérios" (COUTO; COUTO; CRUZ, 2020, p. 212). Nessa premissa, essas pedagogias são "um conjunto de saberes colocados em circulação para orientar e educar as pessoas" (COUTO; COUTO; CRUZ, 2020, p. 212). Assim, é importante considerar que existem discursos produzidos na ocorrência da pandemia e, tal como foi salientado, esses processos da pedagogia existem em qualquer lugar e contexto em que o conhecimento é produzido e essas tais pedagogias existem de modo a codificar a experiência, imprimindo verdades, moldando significados e as estruturas sociais (GIROUX; MCLAREN, 1995).

Nesse sentido, as visualidades propõem uma nova reconfiguração de mundo, de modo que elas circulam em nossas vidas demasiadamente, demandando novos modos de agir, pensar, comportar, comprar, trabalhar e socializar. Desse modo, segundo o professor Raimundo Martins, 
"as imagens mudam de significado quando muda o entorno ou o contexto em que elas são vinculadas" (MARTINS, 2007, p. 28). Sendo assim, ao nos apropriarmos de um discurso próprio do cotidiano e os processos de mudanças nos quais eles ocorrem poderemos reconhecer um escopo abrangente de imagens "pandêmicas".

Essa nova reconfiguração circula em diferentes conjunturas da cultura contemporânea impondo regras sociais, padrões, condutas, atitudes, valores e significados a partir das representações associadas à pandemia, ao vírus e aos protocolos de controle e proteção contra o coronavírus. Desse modo, é imprescindível que se estabeleça uma relação crítica com as imagens, reconhecendo-as como produções contextualizadas, carregadas de sentido e representação (HALL, 2016). Para além do seu valor estético, deve-se buscar reconhecer a imagem a partir da compreensão do seu papel social e na vida da cultura (MARTINS, 2007).

Sob tal perspectiva, destaca-se que "os regimes de visualidade estão ligados, assim, à relação que os grupos, nos quais um observador se insere, estabelece com as imagens, ou seja, ao papel que as imagens desempenham na 'realidade"' (PORTUGAL, 2011, p. 36). Nesse sentido, na atualidade, essas imagens demandam novas configurações, reconfigurando estilos e padrões de vida, trabalhos, consumo, trocas sociais e outros níveis de relações. Ademais,

as imagens se imbricam com os significados e com a dinâmica dos afetos, de modo que a relação homem/imagem é determinada por uma infinidade de regras sociais denominadas regimes de visualidade, ou seja, as formas de representar o mundo visível mudam de acordo com os regimes de visualidade de cada época e de cada lugar. (LOPES; KRAUSS, 2010, p. 257).

Assim, tal como considera Portugal (2011), a partir da experiência empírica e em certas regras atuantes na própria cultura, as nossas experiências de mundo são estruturadas, sendo possível afirmar que, dada a atual conjuntura social, as imagens ensinam, educam e forjam subjetividades voltadas a partir dos protocolos de proteção à saúde, apresentando cartilhas sobre o uso adequado de máscaras, sobre o modo correto de lavar as mãos, bem como a forma de higienizar a casa, roupas e demais utensílios. Esses discursos, ainda, são divulgados por meio de manuais, impressos e digitais, e em guias que dissertam sobre como é o "convívio" da sociedade com o vírus. Esses meios e novos discursos determinam regras e restrições através das quais, segundo Portugal (2011), reconhecemos os regimes de visualidade, os quais conduzem relações e subjetividades dentro de um tempo e espaço definido.

Sendo assim os(as) personagens da Turma da Mônica, e suas respectivas imagens, estiveram voltadas, desde o momento em que foram instituídas as medidas sanitárias de enfrentamento à COVID-19, para narrativas de conscientização, como por exemplo: lavar as mãos com sabonete constantemente, usar máscaras, passar álcool em gel nas mãos, manter o isolamento social e evitar aglomerações. No site eletrônico específico da Turma da Mônica' ${ }^{9}$, criado especialmente para o presente momento, Mauricio de Sousa (2020) destaca que:

Desta vez, nossas histórias, além de entreter e educar as pessoas durante o período de isolamento, também vão ajudar a orientar e a informar as famílias brasileiras. Por isso, estamos trabalhando sem parar, não só para continuar produzindo as histórias dos personagens mais amados do Brasil, mas também para colaborar, desenvolvendo ações que possam, de alguma forma, trazer benefícios para todos os cidadãos. (SOUSA, 2020).

Sob tais discursos, ao observar e analisar esses artefatos, cabe considerar o modo como essa mudança de ênfase dos regimes de visualidade tem exercido com bastante veemência no contexto 
da cultura, de modo que as pedagogias têm efetuado dentro do escopo das visualidades no contexto da pandemia. Além das HQs, publicadas na tentativa de conscientizar, orientar e educar as pessoas, a produção de Maurício de Sousa também disponibilizou, de forma gratuita, desenhos prontos para colorir - passatempos - vídeos e filmes com histórias disponíveis no canal do YouTube ${ }^{10}$ e no site da Turma da Mônica. Essas visualidades dispõem formas de entretenimento, buscando ajudar no "tempo livre" de crianças e adolescentes no confinamento social e no enfrentamento da COVID-19.

Além desses materiais, somam-se também seis cartilhas disponíveis no site (Imagem 2), produzidas especialmente para o enfrentamento da COVID-19. Em cada uma delas, os conteúdos e narrativas estão relacionados a algum assunto referente à pandemia. Sendo protagonizados pelos(as) personagens: Mônica, Cascão, Magali, Cebolinha, Franjinha, Chico Bento, entre outros. Considera-se, assim, que as cartilhas, em seu sentido didático, bem como os discursos e as imagens dos(as) personagens funcionam como guias, instruções e manuais endereçados, sobretudo, para o público infantil. Assim, essas são "práticas pedagógicas nas quais se estabelecem, se regulam e se modificam as relações consigo mesmo e nas quais se constitui a experiência de si” (LARROSA, 1994, p. 44).

Imagem 2 - Cartilhas educativas. Maurício de Sousa Produções, 2020.

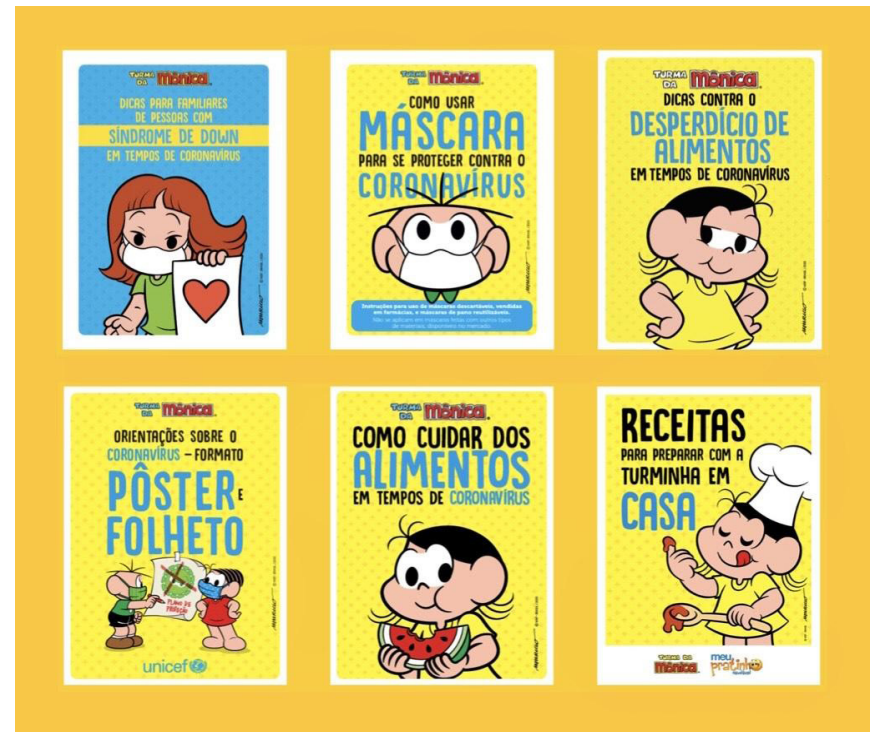

Fonte: Compilação dos autores ${ }^{11}$.

As cartilhas e as visualidades - os(as) personagens - estão ligadas aos sistemas de poder e saber e, como consequência, constroem significações, experiências e conhecimentos de modo a educar e orientar os(as) indivíduos(as) sobre o vírus, sobre o confinamento social e as maneiras de conviver e se proteger em tempos de pandemia. Ao corroborar com o sentido e a potência pedagógica das cartilhas, por exemplo, o estudo de Brum e Magalhães (2019) reforça as possibilidades educativas a partir da apropriação do uso de imagens características do universo de crianças e adolescentes. Segundo o estudo, essas imagens revelam identidades e alteridades as quais poderão, sobretudo a partir do reconhecimento da rede social, alcançar novas possibilidades pedagógicas na medida em que se revelam como imagens de interesse de um determinado público.

Assim, a partir das contribuições de Giroux (1995) essas pedagogias, forjadas a partir do contexto da pandemia, são estabelecidas de modo a produzir narrativas de quem está autorizado a 
falar. As publicações da Turma da Mônica, enquanto artefato produzido dentro da cultura, busca considerar um público específico ${ }^{12}$.

Portanto, as pedagogias culturais, são extremamente políticas, ao forjar condutas e ao reconhecer o impacto das imagens sobre a identidade e a subjetividade, bem como as relações ubíquas envolvendo as visualidades (TOURINHO; MARTINS, 2012). Essas pedagogias procuram "responder às exigências de cada tempo e coloca para a produção certos tipos de sujeito que lhe correspondem, levando adiante o mundo, adaptando-se a ele" (CAMOZZATO, 2014, p. 575).

O personagem Cascão, a partir das análises deste ensaio, reforça a nova ênfase da visualidade do presente e sua "desconstrução" buscando oportunizar novos processos de endereçamento e novos discursos. Assim, se observarmos o histórico das produções de Mauricio de Sousa perceberemos o alcance de diferentes públicos, em que crianças e adolescentes são a maioria. Desse modo, a estrutura e narrativa presentes no personagem Cascão sugerem a subjetivação de um comportamento moldado pela pedagogia metafórica do vírus.

\section{Cascão, nosso embaixador das mãos limpas!}

As imagens criadas pela produção de Mauricio de Sousa encerram perspectivas contundentes acerca dessa mudança de ênfase dos regimes de visualidade, no momento em que as publicações da Turma da Mônica e em especial do personagem Cascão, aqui em questão, assume uma mudança abrupta imposta pela dinâmica social atual. Cascão, assim, se revela como um sujeito que se sensibiliza com as questões que se apresentam em detrimento de suas reais características e subjetividades.

A pedagogia cultural (Imagem 1), se potencializa e se exerce como uma visualidade educativa e provocativa, não na singularidade e originalidade em que ela é criada e operada, ou seja, nas histórias em quadrinhos, mas exatamente quando ela assume uma posição social, política e, sobretudo, de saúde pública, juntando-se à campanha "juntos contra o coronavírus". A reação de surpresa e estranhamento a partir da imagem da higienização do personagem Cascão propõe uma ruptura de narrativas e fomenta novos fluxos de subjetividade. Assim, na perspectiva de Lopes e Krauss (2010), essa aprendizagem acontece na medida que a imagem em questão se desdobra a partir dos direcionamentos sociais que estruturam as experiências.

Isso se dá a partir das circunstâncias postas, em que o Cascão muda seus hábitos e sua identidade original e contribui significativamente para a reflexão acerca das mudanças dos regimes de visualidade. O personagem abre mão de sua invencibilidade e lava as mãos, pois compreende o seu papel e a importância de se manter higienizado. Aqui, o discurso estruturado pelo personagem reconhece a importância de cada um no combate à COVID-19.

Segundo o site especialmente criado para a contextualização das histórias da Turma da Mônica a partir do momento atual: "para mostrar o grau de comprometimento que todos precisaremos ter e dar um bom exemplo para o Brasil, o Cascão dominou o seu medo de água e lavou suas mãos! A arte foi feita especialmente para esta ação". Nessa premissa, a criação do selo digital do personagem contribuiu para a difusão de informações sobre a pandemia e as possibilidades de prevenção contra o vírus, tal como explica a produção de Maurício de Sousa.

\footnotetext{
12 Sob um viés crítico é importante salientar que a realidade abordada pelas cartilhas, bem como as orientações e visualidades compartilhadas, estão voltadas para um tipo de público, delimitando aspectos referentes à própria classe social. Segundo Cunha (2014), "a infância representada pela Turma da Mônica é uma infância idealizada e inocente no sentido de que os personagens são crianças de classe média, felizes e bem alimentadas" (CUNHA, 2014, p. 213). Sendo assim, embora saibamos que as desigualdades sociais se tornaram ainda mais evidentes no contexto da pandemia e que muitos artefatos produzidos pela cultura reforçam essas questões, a ideia central do presente texto não é desconsiderar essa e outras realidades, mas está voltada para a sistematização de uma discussão do modo como as imagens se apropriam do contexto, desenhando novos regimes de visualidade e impulsionado novos processos de representação e comportamento. Por meio da análise de um artefato cultural buscou-se reconhecer novos fluxos de subjetividade frente ao momento presente.
} 
Sendo assim, o personagem desenvolve ações que condizem com a nova ordem pedagógica em questão: quanto aos direcionamentos e obrigatoriedades impostas pela Organização Mundial de Saúde (OMS). De tal modo, a visualidade do Cascão - o selo digital -, assume certa responsabilidade e representatividade ao ser reconhecido como o "embaixador das mãos limpas", sendo essa imagem apropriada e amplamente divulgado em parceria com o Fundo das Nações Unidas para a Infância (UNICEF), com a própria Organização das Nações Unidas (ONU), e outras autoridades da saúde no âmbito nacional, tais como o Ministério da Saúde e a Agência Nacional de Vigilância Sanitária (ANVISA).

Podemos considerar, nesse sentido, que as produções da Turma da Mônica como as cartilhas, bem como a visualidade do personagem Cascão, atuam na governamentalidade, na ideia de políticas públicas, na produção de bons hábitos de saúde e higienização, preservação da vida e conscientização de condutas e atitudes adequadas no combate à pandemia. Dessa maneira elas atuam como "uma máquina que produz subjetivações e somente enquanto tal" são "uma máquina de governo" (AGAMBEN, 2009, p. 46). Nesse sentido, considera-se que essas pedagogias passam, de alguma maneira, a determinar, modelar, controlar e capturar "os gestos, as condutas, as opiniões e os discursos dos seres viventes" (AGAMBEN, 2009, p. 46), uma vez que "a cultura penetra em cada canto da vida social contemporânea, fazendo proliferar ambientes secundários, mediando tudo" (HALL, 1997, p. 22).

Aqui, de modo a compreender a cultura em sua potência e complexidade é necessário lançar olhares sobre as imagens do cotidiano, sobre os modos como elas são produzidas, como se ramificam, potencializam e operam na cultura, construindo "sujeitos, indivíduos, identidades e subjetividades" (TOURINHO; MARTINS, 2012, p. 11). Elas convergem para a política das visualidades, que direcionam e instauram em nossas vidas as condutas e práticas sociais de acordo com as circunstâncias que se apresentam. "A pedagogia entra num processo de atualização constante para conectar-se às exigências e necessidades contemporâneas e, assim, investir, de forma atualizada" (CAMOZZATO, 2014, p. 574), de modo que o papel da produtividade e eficácia da pedagogia está "na fabricação ativa de indivíduos de uma certa experiência de si" (LARROSA, 1994, p. 37).

Essas visualidades, tais como a do personagem Cascão, não apenas representam as circunstâncias cotidianas da pandemia, mas nos formam e educam a partir de suas relações de poder e saber que são postas em funcionamento. Assim, esses artefatos atuam na "tentativa de controlar ao máximo o modo e as relações dos sujeitos, incitando-os a implementarem sobre si uma série de pequenos movimentos" (CAMOZZATO, 2014, p. 574). Os saberes políticos e pedagógicos dessas imagens são usados como controle, conscientização e como um conjunto de restrições, ações, atitudes e modos de ser e se comportar na sociedade.

As pedagogias culturais, nessa perspectiva, entram na dinâmica e na mecânica das "estratégias contemporâneas de produção de governo de pessoas" (CAMOZZATO, 2014, p. 580). Como relembra Foucault (2008), a governamentalidade se define como as práticas de governo que conduzem e orientam a própria conduta e as dos outros, ou seja, um modo de orientar e direcionar, moldar e disciplinar a atitude dos sujeitos. A governamentalidade, aqui, está relacionada aos setores e órgãos públicos nacionais e internacionais, os quais se utilizam da visualidade do personagem Cascão para governar e conscientizar as pessoas. Sendo assim, é possível considerar e reconhecer que as pedagogias culturais, bem como os saberes e significados que circundam à nossa volta "também regulam e organizam nossa conduta e nossas práticas, na medida em que ajudam a fixar regras, normas e convenções, mediante as quais, a vida social é ordenada e governada" (HALL, 1997, p. 4).

Ao observar a mudança abrupta do personagem Cascão e a surpresa ao se deparar com sua flexibilidade e atuação, cabe considerar que essa não foi a primeira vez que o personagem aparece amigável às práticas de higienização e sensível às ações envolvendo a utilização da água. Segundo uma matéria publicada pela Folha de São Paulo, em 2013, Maurício de Sousa já havia escrito um 
pequeno conto em que narra um evento e apresenta um quadrinho em que o Cascão tem o seu primeiro contato com água.

Na ocasião, em 1983, de modo a ajudar as mais de 200 mil pessoas desabrigadas, vítimas de uma das maiores enchentes enfrentadas pelos estados do Rio Grande do Sul, Santa Catarina e do Paraná, várias ações de solidariedade se firmaram em prol da população afetada. Nesse contexto, o conto envolvendo o personagem Cascão, ou seja, a pedagogia cultural, buscou tratar a situação de forma sensível e consciente, em que o personagem rompe seus próprios medos e bloqueios a partir do envolvimento em uma ação social (Imagem 3).

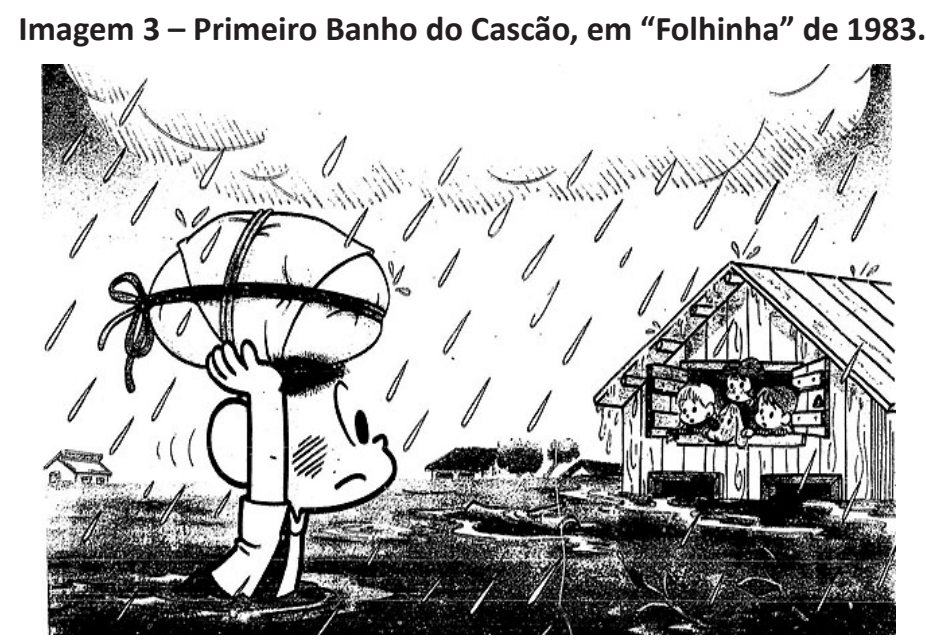

Fonte: Site Folha de São Paulo no UOL ${ }^{13}$.

Segundo a matéria divulgada pela Folha de São Paulo, no dia 31 de julho de 1983, foi publicado por meio da "Folhinha" o texto em que foi narrado o momento em que o Cascão teve o seu "primeiro contato" com a água. Assim, a partir das questões sociais envolvidas, destaca-se o seguinte trecho do conto publicado:

Foi preciso que acontecesse algo mais forte do que uma coelhada da Mônica para ele se decidir. E hoje ele já está pronto para o primeiro banho e para uma ação mais nobre.

Devagarinho, tateando com o dedão. Depois sentindo a água, sensação desconhecida, até os tornozelos. E, em seguida, com a água até a cintura, lá vai o Cascão, com uma trouxinha de roupas e biscoitos, em direção às crianças assustadas, ilhadas pela enchente de Santa Catarina. (Folha de São Paulo, 2013).

Nesse sentido, o momento em que o personagem Cascão tem contato com a água, desde o momento histórico retratado em 1983, apresenta uma visualidade quase que transgressora, a qual muda a ordem natural da própria subjetividade do personagem. Essa mudança de visualidade do personagem, tanto na década de 1980, como no momento atual, propõem, ao mesmo tempo, um processo de sensibilização, em que a vida humana é compreendida a partir de em uma situação de extrema vulnerabilidade. $\mathrm{O}$ jogo de narrativas pedagógicas em questão assume as condições do extremismo do contexto social, de modo que, no ímpeto de consciência e cidadania, "vida e morte" se configuram como a máxima da ação discursiva. Assim, o intervalo de tempo entre esses artefatos visuais e o modo como a imagem do Cascão é ressignificada contribui para uma sociopolítica das 
imagens e das pedagogias. Martins (2013), ao refletir sobre a temporalidade da imagem afirma que, num processo de ir e vir a partir das imagens, algumas contaminações, sobretudo de ordem prática e perceptiva, são facilitadas. Segundo o autor,

essas contaminações geram diálogos com a diversidade através de apropriações, interferências, marginalizações e, até mesmo, silêncios, produzindo espaços onde novos objetos e imagens podem influenciar imaginários sociais e subjetividades individuais. (MARTINS, 2013, p. 85).

O histórico do personagem, nessa perspectiva, encerra apontamentos interessantes no campo das pedagogias culturais e nos regimes de visualidade. Ao analisarmos outras visualidades envolvendo o personagem observa-se muitos outros momentos em que o Cascão entra em "contato" com a água, muitos deles relacionados a sentidos irônicos e metafóricos das histórias da Turma da Mônica, os quais merecerão em outro momento uma análise mais crítica e problematizadora acerca dessas imagens. Contudo, tal como foi evidenciado, buscou-se reconhecer as histórias e visualidades do personagem Cascão como um artefato cultural e o modo como a construção dos discursos e situações vivenciadas pelo personagem encerram narrativas voltadas para o momento presente.

Ademais, de modo a demarcar as possibilidades potenciais do alcance dessas produções, foram compartilhados por meio do site da Turma da Mônica, em parceria com a plataforma de inteligência artificial brasileira Stilingue, dados que afirmam o poder de influência e endereçamento desses artefatos visuais (Imagens 4 e 5). Segundo as divulgações por meio da rede social LinkedIn Corporation, a Mauricio de Sousa Produções realizou mais de 20 ações no digital durante os três primeiros meses de isolamento social. E estes são alguns resultados alcançados no período.

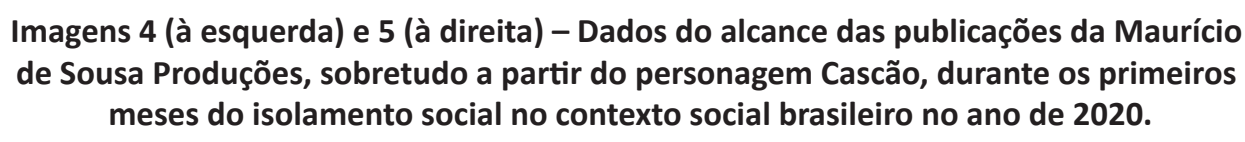
meses do isolamento social no contexto social brasileiro no ano de 2020.
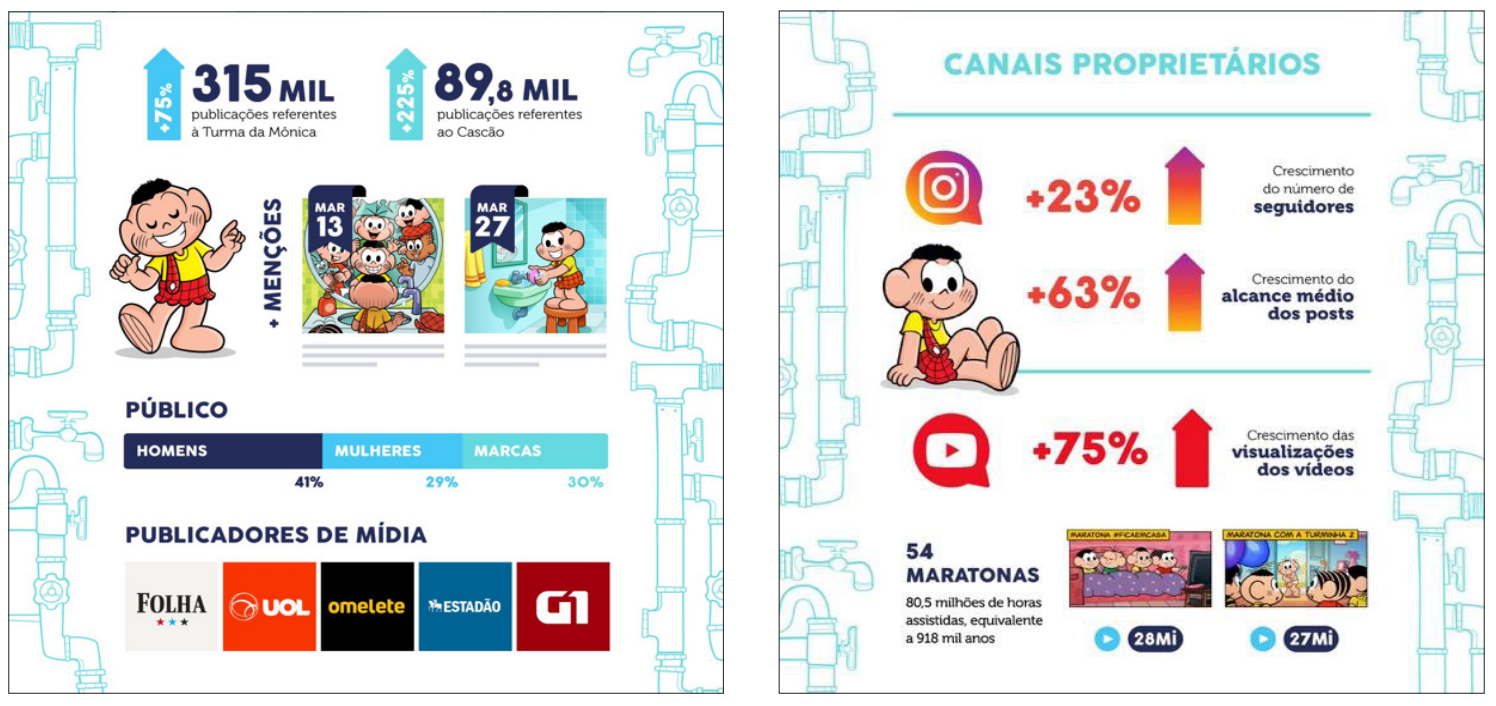

Fonte: Página da Maurício de Sousa Produções no Linkedin ${ }^{14}$.

A partir dos dados apresentados, essas pedagogias, operadas nas redes sociais digitais, podem ser reconhecidas como um mecanismo construtivo e eficiente, sobretudo a partir de um tempo e espaço estabelecido. Segundo os dados apontados, o Instagram da Turma da Mônica teve um

14 Disponível em: https://www.linkedin.com/feed/update/urn:li:activity:6697155629477457920/. Acesso em: 3 nov. 2020. 
crescimento de mais $23 \%$ no número de seguidores(as) e mais de $63 \%$ de alcance nas postagens sobre o Cascão, e no Facebook esse alcance foi de mais de 57\%.

Somado a esses índices, no canal do YouTube ${ }^{15}$ da Turma da Mônica o crescimento foi de mais de $75 \%$ de visualizações dos vídeos disponibilizados publicamente no canal. Foram 80,5 milhões de horas assistidas, equivalente a 918 mil anos. Já sobre a visualidade do Cascão, foram mais de 225\%, equivalente a 89,9 milhões de publicações referentes ao personagem, especificamente quanto ao seu selo digital: “Cascão, nosso embaixador das mãos limpas!”. As publicações se deram em diferentes mídias digitais: redes sociais, jornais, sites de entretenimento e entre outros meios de compartilhamento de conteúdos.

Partindo dos dados apresentados e das discussões aqui sistematizadas, nos cabe reconhecer e refletir sobre o poder das visualidades e dos processos operacionais dessas pedagogias dentro da cultura, as quais se polarizam e ramificam nas redes sociais digitais. Elas se estabelecem como arenas de culturas visuais, como produtividade, fabricação de sujeitos, condutas, discursos, verdades, modos de ser, agir, pensar e se comportar em tempos de pandemia. Sob esse contexto, a visualidade do Cascão é operada em larga escala nas mídias sociais digitais, pois sua força e potência pedagógica atingem públicos de diferentes lugares e grupos variados - apesar de estarem endereçadas ao público infantil e de serem produzidas a partir de uma classe social definida. Tal potência corrobora, assim, com a difusão de conhecimentos e experiências, as quais, de certa forma, partem das imagens criativas, alegres, engraçadas e sedutoras das histórias dos(as) personagens da Turma da Mônica. Essas imagens incidem sobre as relações de si, sendo uma pedagogia para além do entretenimento, demarcando novas possibilidades de aprendizagem por meio da sua utilização e abordagem crítica no contexto educacional.

\section{Considerações Finais}

Sabe-se que as imagens, enquanto artefatos culturais, produzem discursos e reforçam subjetividades, sendo estas "instâncias culturais que também são pedagógicas, também ensinam alguma coisa” (SILVA, 2009, p. 139). Desse modo as imagens, tal como considera Stuart Hall (2016), poderão ser problematizadas sob um viés crítico, histórico e social.

Nessa perspectiva, considera-se que, com notabilidade os(as) personagens criados(as) por Mauricio de Sousa encerram narrativas presentes em meio aos diversos contextos da sociedade brasileira, demarcando possibilidades contundentes na escola. Ou seja, tais personagens, conforme Cunha (2014), são compreendidos(as) como uma instituição, tal é o modo como ensinam e instituem práticas sociais e culturais.

Assim, ao reconhecer o espaço escolar, em especial o da educação infantil e dos anos iniciais do ensino fundamental, considerando o modo de circulação dos gibis da Turma da Mônica, identifica-se que tais artefatos assumem visualidades e discursos pedagógicos apoiados nos processos de ensino e de aprendizado, sejam aqueles voltados aos projetos e atividades de alfabetização e letramento, ou mesmo para serem usados para decoração dos espaços. Ademais, é possível considerar que, embora estejam disponíveis aos alunos e alunas os diversos recursos midiáticos e virtuais na sociedade contemporânea, os gibis ainda se revelam como artefatos de interesse do público infantil, ainda mais quando esse interesse é potencializado pelos(as) professores(as) em meio às suas práticas em sala de aula.

A reverberação das pedagogias culturais criadas por Mauricio de Sousa, oportuniza novos discursos e subjetividades, tanto pela predileção quanto pela apropriação das características dos(as) personagens em meio à diversidade das características da sociedade. Aqui, a pedagogia do 
personagem Cascão encerra um discurso que exemplifica a mudança dos regimes de visualidade, na medida que o momento presente se impõe de forma categórica, impulsionando novos valores para a dinâmica social. Assim, a imagem do Cascão, denominada e apresentada como "O Nosso Embaixador das Mãos Limpas!”, opera na cultura, determinando e educando sujeitos, corpos, atitudes, valores e medidas de enfrentamento e confinamento frente ao contexto da pandemia da COVID-19.

\section{Referências}

AGAMBEN, Giorgio. O que é o contemporâneo? e outros ensaios. Chapecó: Ed. Argos, 2009.

BRUM, Lucas Pacheco; MAGALHÃES, Marcos Vinícius. Cartilha pedagógica: potências pedagógicas entre visualidades. Revista da FUNDARTE, Montenegro, v. 39, n. 39, p. 149-167, jul./dez. 2019.

CAMOZZATO, Viviane Cardoso. Pedagogias do Presente. Educação \& Realidade, Porto Alegre, v. 39, n. 2, p. 573-593, abr./jun. 2014.

CASCÃO tomou o primeiro banho há 30 anos; leia conto de Mauricio de Sousa. Folhinha, Folha de São Paulo, São Paulo, 18 jul. 2013. Disponível em: https://m.folha.uol.com.br/folhinha/2013/07/1312672-cascao-tomou-o-primeiro-banho-ha-30-anos-leia-conto-de-mauricio-de-sousa.shtml. Acesso em: 10 nov. 2020.

COSTA, Marisa, Vorraber. Sobre a Contribuição das Análises Culturais para a Formação de Professores no Início do Século XXI. Educar em Revista, Curitiba, v. 37, n. 37, p. 129-152, ago./maio 2010.

COSTA, Marisa, Vorraber; VEIGA-NETO, Alfredo (org). Estudos Culturais em Educação: mídia, arquitetura, brinquedo, biologia, literatura, cinema... Porto Alegre: Ed. da UFRGS, 2004.

COUTO, Edvaldo Souza; COUTO, Edilece Souza; CRUZ, Ingrid de Magalhães Porto. \#FIQUEEMCASA: EDUCAÇÃO NA PANDEMIA DA COVID-19. Interfaces Científicas, Aracaju, v. 8, n. 3, p. 200-217, 2020.

CUNHA, Susana Rangel Vieira da. Imagens na educação infantil como Pedagogias Culturais. In: MARTINS, Raimundo; TOURINHO, Irene (org.). Pedagogias Culturais. Santa Maria: Ed. da UFSM, 2014. p. 199-223.

FOUCAULT, Michel. Segurança, território, população: curso no Collège de France (1977-1978). São Paulo: Martins Fontes, 2008.

GIROUX, Henry Armand. Memória e Pedagogia no Maravilhoso Mundo da Disney. In: SILVA, Tomaz Tadeu da (org.). Alienígenas na sala de aula: uma introdução aos Estudos Culturais em Educação. Petrópolis: Vozes, 1995. p. 132-158.

GIROUX, Henry Armand; MCLAREN, Peter L. Por uma pedagogia crítica da representação. In: SILVA, Tomaz Tadeu; MOREIRA, Antônio Flávio (org.). Territórios contestados: o currículo e os novos mapas culturais. Petrópolis: Vozes, 1995. p. 144-158.

GUAREZI, Daniela Jeremias. Os gibis da Turma da Mônica como apoio para o letramento e a alfabetização. 2016. Trabalho de Conclusão de Curso (Licenciatura em Pedagogia) - Universidade Federal de Santa Catarina, Florianópolis, 2016.

HALL, Stuart. A centralidade da cultura: notas sobre as revoluções culturais do nosso tempo. Educação \& Realidade, Porto Alegre, v. 22, n. 2, p. 15-46, jul./dez. 1997.

HALL, Stuart. Cultura e representação. Rio de Janeiro: Ed. PUC-Rio: Apicuri, 2016.

HALL, Stuart. A identidade cultural na pós-modernidade. 12. ed. Rio de Janeiro: Lamparina, 2019.

HERNÁNDEZ, Fernando. A Cultura Visual como um convite à deslocalização do olhar e ao reposicionamento do sujeito. In: MARTINS, Raimundo; TOURINHO, Irene (org.). Educação da Cultura Visual: conceitos e contextos. Santa Maria: Ed. da UFSM, 2011. p. 31-49.

KELLNER, Douglas. A Cultura da Mídia - estudos culturais: identidade e política entre o moderno e o pós-moderno. São Paulo: Ed. EDUSC, 2001.

LARROSA, Jorge. Tecnologia do eu e educação. In: SILVA, Tomaz Tadeu da. O sujeito da educação: estudos foucoultianos. Petrópolis: Vozes, 1994. p. 35-86. 
LOPES, Marcelo Silvio; KRAUSS, Regina. O sujeito e a visualidade: Parábolas do olhar contemporâneo. Visualidades, Goiânia, v. 8, n. 2, p. 251-267, jul./dez. 2010.

MARTINS, Raimundo. A cultura visual e a construção social da arte, da imagem e das práticas do ver. In: Oliveira, Marilda (org.). Arte, educação e cultura. Santa Maria: UFSM, 2007. p. 19-40.

MARTINS, Raimundo. Metodologias visuais: com imagens e sobre imagens. In: DIAS, Belidson; IRWIN, Rita L. (org.). Pesquisa educacional baseada em arte: a/r/tografia. Santa Maria: Ed. da UFSM, 2013. p.83-95.

MATTELART, Armand; NEVEU, Érik. Introdução aos Estudos Culturais. São Paulo: Parábola Editorial, 2004.

MAURICIO DE SOUSA PRODUÇÕES. Juntos contra o coronavírus. [S. l.]: Mauricio de Sousa Produções, 2020. Disponível em: https://turmadamonica.uol.com.br/juntoscontraocoronavirus/. Acesso em: 25 nov. 2020.

MIRZOEFF, Nicolas. Una introdución a la cultura visual. Barcelona: Editora Paidós, 2003.

PORTUGAL, Daniel B. O realismo entre as tecnologias da imagem e os regimes de visualidade: fotografia, cinema e a “virada imagética" do século XIX. Discursos fotográficos, Londrina, v. 7, n. 11, p. 33-54, jul./dez. 2011.

SANTANA, Erivelton Nonato de. Gibi, o aparelho ideológico quadrinizado: considerações sobre a diversidade discursiva e o caráter instrutivo-educativo nas histórias da Turma da Mônica. 2007. Tese (Doutorado em Letras e Linguística) Universidade Federal da Bahia, Salvador, 2007.

SANTOS, Boaventura de Sousa. A cruel pedagogia do vírus. Coimbra: Almedina, 2020. E-book. Disponível em: https:// www.abennacional.org.br/site/wp-content/uploads/2020/04/Livro_Boaventura.pdf. Acesso em: 29 nov. 2020.

SILVA, Tomaz Tadeu da. Documentos e identidade: uma introdução às teorias do currículo. Belo Horizonte: Autêntica, 2009.

STEINBERG, Shirley; KINCHELOE, Joe (org.). Cultura infantil: a construção corporativa da infância. 2. ed. Rio de Janeiro: Civilização Brasileira, 2004.

STEINBERG, Shirley R. Kindercultura: a construção da infância pelas grandes corporações. In: SILVA, Luiz Heron da; AZEVEDO, José Clóvis de; SANTOS, Edmilson Santos dos (org.). Identidade Social e a Construção do Conhecimento. Porto Alegre: SMED, 1997. p. 98-145.

TOURINHO, Irene; MARTINS, Raimundo. Entrevidas das imagens na arte e na educação. In: MARTINS, Raimundo; TOURINHO, Irene (org.). Cultura das Imagens. Santa Maria: Ed. da UFSM, 2012. p. 09-13.

Data de submissão: 31/01/2021

Data de aceite: $18 / 04 / 2021$ 